\title{
The Factors that Affect Qatari College Students' Motivation and Attitudes to Learn English
}

\author{
Dr. Sabah Salman Sabbah \\ Assistant Professor, Community College of Qatar \\ Email:dr.sabshl@gmail.com
}

\author{
Doi:10.5901/mjss.2017.v8n1p259
}

\begin{abstract}
This qualitative study investigated the factors that affected the motivation and receptivity of English as a second language of female students who enrolled in the English Language center of the Foundation Program in the Community College of Qatar in the academic year 2015/2016. Besides, the study attempted to identify the mechanisms that are used by families, teachers, college administrators, and classmates that motivate or demotivate the students. Finally, the study tried to identify how the classroom environment impacted students' motivation. Semi-structured interviews were conducted with 8 students in different ESL levels in which the participants were asked different questions related to the impact of five dimensions on the respondents' motivation to learn English. These dimensions are concerned about family impact, teachers' impact, administrators' impact, classmates' impact, and impact of the respondents' willingness and goals to learn the target language. The questions were validated by a jury of five specialists in teaching and educational psychology prior to the interviews. The interviews were recorded, transliterated, and analyzed manually and by Atlas.it software. Codes and categories were established based on the interviews. Frequencies of words, verbs and adjectives used by the respondents in their talk, were calculated. Results showed that students' were affected by all the above-mentioned dimensions at different proportions. The results also depicted the importance of the necessity to provide help, encouragement and emotional support to students by their socio-cultural relationships with their families, teachers, administrators and classmates.
\end{abstract}

Keywords: motivation, attitudes, parents' effect, psychology

\section{Introduction}

Literature review of second language learning revealed that students' receptivity, willingness to learn a new language and to be acquainted to a new culture or to the native speakers of the target language are affected by different social and psychological factors among which are students' anxiety, competitiveness, fear of success, motivation and self-esteem (Celce-Murcia 1991; Brown 1994; Richards, \& Rogers 1986). "Motivation has been widely accepted by both teachers and researchers as one of the key factors that influences the rate and success of second/foreign language (L2) learning." (Dörnyei, 1998: 117). Students' motivation is in turn affected by the social context of the L2 learners (Dornyei, 2001).) Some studies demonstrated the role of social relations in determining academic engagement (Kindermann, 2007) and influencing English as L2 learners' motivation (Abdesslem, 2002). Thus, to probe the students' motivation to learn another language, it is essential to identify the social relations with the people surrounding them like parents, teachers, and classmates. With its two dimensions, namely integrative and instrumental, motivation is indirectly associated to the reasons why an individual in his/her socio-cultural context would be engaged in doing a particular activity as learning a second language( Daddi, 2011:1). Hence, the existence or lack of the teachers', parents', husbands' kind behaviors, encouragement, rewards, appreciation or offensive expressions, and negative evaluations may influence students' motivation either negatively or positively. In this study, the researcher tried to explore how all these factors affect Arab college students learning English.

\section{Literature Review}

Researchers have not agreed on a definition of motivation. As Gardner (2001: 242) explains: "motivation is a very complex phenomenon with many facets... Thus, it is not possible to give a simple definition." However, Dornyei (2001) pinpoints that motivation is responsible for "why people decide to do what they do, how long they are willing to sustain the activity and how hard they are going to pursue it" (2001: 8). Dejnozka and Kapel (1991) define motivation as "a psychological concept in human behavior that describes a predisposition reward a particular" (p.61).

According to Gardner (1998), the study of motivation includes: the learner's attitude towards the target language, 
the desire to learn the language and the intensity of the engagement. Dornyei (2001) asserts that 'motivational teaching practices' affect students' willingness to study a second language.

The different dichotomies of motivation: intrinsic/extrinsic and integrative/ instrumental correlate with classroom interaction . "Integrative motivation" refers to the learner's wish to learn L2 in order to relate better to and integrate well with speakers of the target language. In contrast, instrumental motivation refers to the learner's state when he learns language for academic success or perhaps to get a job for which there is a language requirement. Research finds out that strongly-motivated student tends to spend more time working outside class (doing homework) and to participate in classroom activities as well. Research also finds out that learners with integrative motivation tend to be more active in class, volunteering more, and making more correct responses. So their receptivity will be better (Gardner, 2006). Gardener (2006: 243) adds that "if one is motivated, s/he has reasons (motives) for engaging in the relevant activities, expends effort, persists in the activities, attends to the tasks, shows desire to achieve the goal and enjoys the activities." Deci and Ryan (1994) maintained that an instrumental type of motivation can become a high source of motivation. Studies seem to support that instrumental motivation is more appropriate to L2 learning (Norris-Holt, 2001). Dornyei developed a list of 10 'motivational macro-strategies', which were called the 'Ten commandments for motivating language learners'. They are quoted from Dornyei (1998) as follows:

1. Set a personal example with your own behaviour.

2. Create a pleasant, relaxed atmosphere in the classroom.

3. Present the tasks properly.

4. Develop a good relationship with the learners.

5. Increase the learners' linguistic self-confidence.

6. Make the language classes interesting.

7. Promote learner autonomy.

8. Personalize the learning process.

9. Increase the learners' goal-orientedness.

10. Familiarize learners with the target language culture.

Literature review shows that motivation to learn a second language is influenced by the learners' attitudes towards the group of the native speakers as well as the learner's orientation towards the learning task itself $(1972, p .3)$. On the other hand, Krashen (2002) used the term "Affective Filter" to hypothesize that an input rich environment is required where the learners can be relaxed, motivated and self-confident in acquiring the second language successfully. In other words, teachers' and classmates behaviors along with the classroom environment might be driving force or barriers to student's motivation to learn. Based on these aspects, researchers have been investigating different aspects of the motivation issue inside the classroom. Some have studied the effect of the instructional materials (Balkır \& Topkaya, 2009; Ajibade \& Ndububa, 2008). Some others highlighted the effect of instructional strategies and teachers' behaviours in and outside the classroom (Guilloteaux \& Dörnyei, 2008). Others probed the impact of learning environments and the power of student choice (Wu \& Wu, 2008), and student goal setting (Melendy, 2008).

Some researchers studied the notion of goal pursuit and how it affects motivation (Wigfield, 1994). Boekaerts, de Koning \& Vedder, (2006) For young learners, goals are most likely to originate from social interaction with significant others, including parents and siblings(cited in Daddy 2011: 17)

Literature review also reveals that there are a few studies conducted in the Arab world to identify the factors that affect students' motivation to learn a second language. For example, Qashoa (2006) designed a questionnaire to 100 secondary school students in Dubai. One of its purposes is to study these factors. Qashoa interviewed 20 students and 3 supervisors. The findings showed that students have a higher degree of instrumentality than integrativeness. Also, the results indicated that difficulties of vocabulary, structures and spelling teaching material were the most demotivating factors for the students. Similarly, Al-Quyadi (2000) investigated Sana'a University English students' motivation and attitudes towards learning English; the results of the questionnaire he used on the 518 students showed that the students had both instrumental and integrative motivation and positive attitudes to learn English. Likewise, Tahaineh and Daana(2013) studied Jordanian students' motivation and attitudes to learn English and found out that their 184 university participants were integratively- motivated. To the best knowledge of the current researcher, only one study in the Arab context has explored the factors that affect students' motivation to learn. It is Daddy (2011) who highlighted the impact of parents, teachers, administrators classmates and class physical environment on students learning English. On the other hand, Karahan (2007) investigated Turkish students' motivation.. The results indicated that students had mildly positive attitudes; especially female students had higher rates. Similarly, Vaezi (2008) claimed that Iranian students had very high motivation and positive attitudes towards learning English and they were more instrumentally motivated.

The previously-mentioned review shows that the current study might be the second one in the Arab countries and 
the first one in Qatar that explored the factors that enhance students' motivation at tertiary level.

\section{Methodology}

\subsection{Problem of the study}

The main reason of this study emerged from the complaints raised by learners, teachers, administrators, and parents indicating that most of ESL students enrolling in the foundation program in the Community College of Qatar cannot attain the desired level of proficiency in English. Theoretically, most instructors hypothesized that this situation is attributed to the lack of motivation. Thus, as an instructor in this program, the researcher attempted to probe the factors that may hinder or enhance students' motivation to learn English. This study was a part of a big project in CCQ where two instructors, among whom was the current researcher, administered a 40-item questionnaire to identify the students' motivation orientation. Due to the length and the large bulk of analysis, the quantitative part will be published later. Meanwhile, the current researcher preferred to spend her own time and effort to investigate qualitatively the factors that affect students' motivation and so interviewed a sample selected randomly from the original 100 students of the quantitative part of the study.

The current study followed a rigorous data collection protocol by employing a qualitative approach utilizing ideas gathered from interviews with the study subjects.

\subsection{Sample of the study}

The sample consisted of 8 students selected from the 100 students who answered the questionnaire in the first phase of the project, namely the quantitative phase. The subjects enrolled in different ESL levels ranging from level 1-level 4.

\subsection{The study questions}

The study attempted to answer the following questions:

1. "What are the participants' perspectives of the factors that can enhance their motivation to learn English?"

2. What are the mechanisms that are adopted by families, teachers, college administrators, and classmates that enhance or hinder the students' motivation.

3. How does the classroom environment affect students' motivation?

\subsection{Study Instrument}

In order to answer this question, the researcher used in-depth semi-structured interviews. Although conducting interviews is a time-consuming process that requires careful planning (Cohen, 2006), the researcher did not use a questionnaire to explore the study subjects' perspectives of motivation enhancement for two reasons. First, the subjects of this study were exposed to such a study instrument to answer the quantitative part of the research project. Secondly, the questionnaire might not be the appropriate way to investigate the participants' perspectives especially as it would hinder the flexibility of the participants to express themselves. (Adams and Cox, 2008). The rationale behind using interviews as an instrument for this study lies in the fact that such instruments help researchers "to obtain more detailed and thorough information on a topic than it might be gleaned from a questionnaire". (Adams and Cox, 2008:21). Interviews are well suited to the exploration of attitudes, values, beliefs and motives (Richardson et al., 1965; Smith, 1975(as cited in Barriball and While, 1994:329). In addition, Gordon (1975) pointed out that interviews provide the opportunity to evaluate the validity of the respondent's answers by observing non-verbal indicators, which is particularly useful when discussing sensitive issues (as cited in Barriball and While, 1994:329).

Although interviews lie in a continuum of being structured to non-structured, the one used in this study is a semistructured interview. There were two considerations that made the current researcher use the semi-structured interviews as a means of data collection.

1. According to Adams and Cox (2008:29), "the interviews uncovered an array of interesting issues that, because of their sensitive nature, would never have been identified through a questionnaire." A semi-structured interview is a qualitative method that permits the researcher to prepare a list of open questions (questions that prompt discussion) or topics beforehand, guiding researchers to advance with the interview more accurately with the opportunity for the interviewer to further explore particular themes or responses. 
2. The semi-structured interviews enable probing for more information and clarification of answers. They enable students to speak freely (Troudi and Alwan, 2010).

3. They are standardized methods of collecting data. Gordon, 1975 (as cited in Bargn and Whiles, 1996) argued that the wording and sequence of all the questions in a standardized intervention are exactly the same for each respondent. Thus, researchers can ensure that any differences in the answers are due to differences among the respondents rather than in the questions asked.

4. Semi-structured interviews have high validity as the respondents are able to talk about something in detail and depth. The meanings behind an action may be revealed as the interviewees are able to speak for themselves with little direction from interviewer.

5. Semi-structured interviews tend to elicit more open-ended, rambling responses that often require several codes simultaneously. (Campbell, Quincy, Osserman, and Pedersen, 2013:297).

\subsection{The Stages of conducting the interview}

\subsubsection{Pre-interview stage}

This stage included the following actions: identifying respondents, deciding on the number of interviews and preparing the interviews. (Laforest, 2009). Deciding on the number of interviewees was based on two underpinnings. The first was based on Laforest's argument (2009: 2), "It may be sufficient to conduct only a few interviews with key informants from the study community methods when semi structured interviews may be viewed as a way of supplementing other data collection. On the other hand, there was a research-based tendency (Strommen and Mates, 2004; Abdulla, 2005 and Meyers 2009) "to view interviewees as proportionately much smaller than questionnaires respondents, normally ranging from 6\% to 20\%". (as cited in Dady,2011:93 )

Based on the above-mentioned research-based arguments, a systematic sampling was used to randomly choose 8 students (2 from each level, 1,2,3,4 from the sample of the study $(n=100)$ that had answered the questionnaire for finding out their type of motivation. This sample constituted $8 \%$ of the whole sample of the study. To choose them, the researcher visited the evening classes whose students answered the questionnaire. The students were told about the objectives of the interviews. Then, the researcher picked up every $9^{\text {th }}$ or $10^{\text {th }}$ student based on the total number of the class after excluding the students who did not show any enthusiasm in participating as interviews respondents.

Even though semi-structured interviews are flexible, they require rigorous preparation (as cited in Dady, 2011:93; Laforst, 2009:3). To prepare the interview, the researcher started by working out a set of questions beforehand to be asked to the respondents as one of the merits of semi-structured interviews is standardizing the questions. Standardization, here, is achieved in meanings rather than wording or formulating the questions.

According to Gardner (1985) there are three key components of L2 motivation: 'motivational intensity or effort", "desire to learn the language" and "attitudes towards learning the language" (Dörnyei and Ushioda, 2011:41). Through the literature review conducted for this study, the researchers found out that the desire, efforts and attitudes that Gardner pointed to are, in fact, influenced by certain factors or "sources of influence" if we quote Dadi' words (2011:161). These sources of effects that seem to have a great impact on students' motivation to acquire knowledge in general and to learn languages in particular are:

1. The respondent's family: This includes parents, siblings, husbands and kids as some of the study participants are married.

2. The respondent's teachers at college, namely ESL department in the Community College of Qatar.

3. The Administrative affairs in CCQ: This includes the stakeholders, rules, policies, regulations, plans and the facilities provided to students.

4. The respondent's classroom climate: This includes the classmates, the classroom setting, namely the class size, furniture and teaching facilities.

5. The respondent herself: This includes her long-term goals, her strategies to improve her language skills, her academic potentials and psychological circumstances.

6. Under each domain, five to six questions were raised during the interviews. (Appendix B)

\subsubsection{Establishing the interviews reliability}

The reliability of the interview was established by the standardization of the procedures and questions (Silverman, 1993). The researcher applied the strategies suggested by Silverman (1993) and used by Dadi (2011: 97) to establish the 
reliability. First, standardization was guaranteed by asking all the respondents the same questions (meaning not wording) and by providing them with sufficient time for answering. The same recording device was used to record the interviews, namely the researcher's mobile. Arabic was the language used in all the interviews regardless of the students' level. This was part of standardization, especially as the interviewees are academically and professionally unequal. Level 1 and 2 students could not understand and speak English fluently. Therefore, the researcher decided to use Arabic with all the respondents. To maintain standardization, the interviews were translated and transcribed by the researcher and by another Arab ESL instructor. In addition, the researcher used a standardized protocol as suggested by Silverman (1993:93). Thus, the interviewer (the researcher herself) did not show any sign of surprise or disapproval during the interview. Paraphrasing was used if a respondent could not understand the question. Furthermore, the same introductory message was constantly used in all interviews. (Appendix C)

Related to the planning stage were implementing the codes of ethics and deciding on the convenient setting and mode for the interviews (Denzin and Lincolin, 2011:65). To guarantee one of the ethical preconditions, the researcher of the current study got the approval to conduct the interviews from the Chair of the ESL department and the instructors who teach the classes from which the study participants were chosen. As all respondents enrolled in the evening classes, the interviews were conducted on four days. Each student was interviewed for 40 minutes including establishing the rapport necessary to create trust between the interviewer (the researcher) and each respondent. The researcher asked for the ESL Chair's and the instructors' permission to excuse the selected study subjects to leave at the last 10 minutes from the class time. This 10 minutes plus the 30-minute break was the real duration for each interview. It was decided that each student would be interviewed alone at the researcher's office. The researcher ensured that the interviewers would not hear each others' answers so as to assure confidentiality. The researcher also planned to use her mobile to record the interviews.

\subsubsection{The arrival stage}

As a continuation of applying the codes of ethics, each interviewee was briefed about the purpose of the interview upon her arrival to the office. The researcher informed each respondent about the duration and the format of the interview. Before starting the interview, the researcher tried to build trust, confidence and feeling of safety for each respondent, that she would not be harmed physically, psychologically or socially (Shank and Brown, 2007). They were asserted that confidentiality, honesty and absence of deception are integral parts of the research. Thus, the researcher ensured each student individually that her anonymity and privacy would be protected. Therefore, they could speak freely and frankly. After considering all these ethical issues and upon the students' approval to record the interviews, they were asked to sign a consent form that they voluntarily agreed that their conversations on the interview questions would be recorded. (Appendix A).

\subsubsection{Starting the interview}

After building a rapport with each respondent, the interviewer started asking the questions and probing some questions from the students' answers. The interviews flowed naturally like conversations. Meanwhile, the interviewer tried to observe the students' paralinguistic signs, i.e. their facial expressions and gestures as these reflect, to some degrees, their attitudes towards the topic.

\section{Results}

\subsection{Analyzing the interviews}

The researcher used on-going process of analysis. Each interview was directly translated and transcribed. It was intended to sometimes use literal translation so as not to lose the exact meanings of some words that the respondents used. For example, a student used the word "Farfush"-(funny) - to describe the sort of teachers who would enhance their motivation. Some students hesitated when talking about administration. This appeared in the use of speech fillers as "mmmmmmm" which indicates reluctance to speak or lack of knowledge. The on-going analysis helped the researcher to find initial and conceptual codes of the respondents' answers. This initial interpretation was subjected to change when implementing a second coding after all the interviews were done. All in all, the data analysis was based on interpretive and grounded theory approach as proposed by Stauss and Corbin (1990). It is a set of rigorous research inductive procedures leading to the emergence of conceptual categories. Strauss and Corbin (1990:7) pointed out that the three 
basic elements of grounded theory are concepts (or codes), categories (or themes), and propositions. Categories are higher in level and more abstract than the concepts they represent. The grouping of concepts forms categories. Propositions indicate generalized relationships between a category and its concepts and between discrete categories (as cited in Pandit, 1996; Noble and Smith, 2013). To establish the coding reliability, the researcher used intercoder reliability as suggested by Popping (2010:1069). This reliability requires that two or more equally capable coders operating in isolation from each other select the same code for the same unit of text (Popping 2010:1069). The researcher asked a friend of hers to analyze the transcribed interviews and select codes. The results of her analysis and the researcher's were the same in many aspects.

The first step in data analysis was using in-vivo coding where the same words or short phrases are taken from the data itself without any change. To do so, the researcher used colored pens and highlighter to highlight the codes in the respondents' answers. The aim of creating an in-vivo code is to ensure that concepts stay as close as possible to the respondents' own words or use their own terms because they capture a key element of what is being described (King, 2008). Then, the researcher used "open coding" where concepts in the interview scripted data were labeled and categorized (Pandit, 1996). To achieve this, data was initially broken down by asking simple questions such as what, where, how, when, how much, etc. following Pandit's technique, 1996. Subsequently, the data were compared and similar incidents are grouped together and given the same conceptual label. Appendices 2, 3, 4, 5, and 6 show examples of quotations, codes derived from quotations and themes categorized from a group of codes. Memos, the theorizing write up of ideas about codes and their relationships, were also created. At the end, prepositions were inductively reached to. Those prepositions involved the grounded theory that the researcher derived. According to Glaser and Strauss, 1967 (as cited in Pandit, 1996) prepositions are similar to hypotheses in quantitative research.

In this research, some parts of the transcribed data were analyzed using the qualitative data analysis software package ATLAS.it. According to Lee and Fielding (1991:1), "there has recently been considerable progress in the analysis of qualitative data using a variety of specially written computer programs."

\subsubsection{Results relating to the respondents' perspectives of the role of teachers to enhance their motivation}

During the thorough analysis of the interviews, the researcher found out that all the respondents used certain adjectives and action verbs repeatedly that reveal their perspectives of the sort of teachers, administrative staff, families and classmates who enhance their motivation. These were the underpinnings that helped the researcher to identify codes. The following tables show some of these adjectives and actions. It is worth noting that this analysis technique of finding out adjectives and words of action has been used by Dadi, 2011.

Table (1): Adjectives and action verbs used by respondents to describe the sort of teachers who enhance their motivation.

\begin{tabular}{|l|l|}
\hline Adjectives & Actions \\
\hline Positive adjectives: Fair, friendly, flexible, & Respect us, respect our culture, reinforce, teach well, reward, advise, teach us \\
enthusiastic, self-confident, willing to help, proficient & learning strategies, socialize with students, urge, make students love English, treat \\
in English, funny, kind, respectful, cheerful, active, & us like a parent, help us to overcome our difficulties, correct test paper fairly, not to \\
sociable, not nervous, patient, lenient, creative, & write questions above our level, encourage us, respect our opinions, vary \\
facilitator, easy in teaching, competent, & techniques, use teaching aids, give handouts, give activities and practice, make \\
knowledgeable, encouraging, inspirational, good & class lively, use technology, give exam feedback, plan well, show sense of humor, \\
planner, humble, never late to class, culturally & use modern teaching methods, tutor them, prompt us to be creative, create a \\
sensitive, smiling, be Qatari. & cheerful classroom climate, help us to be independent learners, make us feel sense \\
Negative adjectives: frustrating, sarcastic, & of achievement, enhance our attitude to learn English, not mocking students, \\
nervous, too strict, disrespectful, biased, & manage the class properly, value students' participation, communicate with \\
threatening, arrogant, bored, & students, not embarrassing students, have attitude, come early to class. \\
\hline
\end{tabular}

When asked whether they find foreign teachers or Arab teachers enhance their motivation more, four students express their preference of having Qatari teachers rather than foreign teachers. They associated this with the fact that the Qatari teachers respect students' culture more. Two students express their preference of foreign teachers. They justified this by stressing the idea that they need English native speakers to help them acquire the British or American accent. Two other students showed no preference of the teacher's nationality as far as the teacher is proficient in speaking English and has pedagogical competence. Following are some quotations from the interviews: Quotation (1): 
Researcher: do you like the teacher to be a foreigner or an Arab?

Student: A foreigner because this helps me to communicate with him more in English.

Researcher: Suppose that you have two very proficient teachers but one is English native speaker and the other is an Arab teacher but he is very proficient in English. Which do you prefer more/

Student: Also I prefer the English native speaker.

Researcher: Why?

Student: Because if he is an Arab teacher, I will keep talking to him in Arabic. But, when he is foreigner, I will be obliged to speak English with him.

Quotation(2):

Researcher: what will enhance your motivation more; being taught by an English native-speaking teachers or Arabic speaking teachers but with native-like proficiency?

Student: I don't care if the he teaches me well; respect me, and the most important thing to respect my culture. But I think the foreigner teacher can force us to speak English.

Two of the teacher's characteristics that have been used repeatedly by the respondents was related to "respect us and our culture" and "sense of humor-being funny". Following is a quotation extracted from the interviews:

Student: To listen to me and to respect me in class. If there is respect between students and teachers this will make them like the class more. And I want the teacher to have sense of humor. The class should be funny sometimes.

\subsubsection{Results relating to the respondents' perspectives of the role of administration to enhance their motivation:}

To my amazement as a researcher, instructor and interviewer at the same time, many respondents hesitated to talk about the administration role in enhancing their motivation. Two of the students said that the administration has nothing to do to motivate students. Then, by using probing questions they declared what they seemed to hide. Unanimously, they agreed that flexibility and consideration to students' circumstances is the most important factor in enhancing their motivation. They stressed on the attendance policies. Two students complained how they are marked absent while they were admitted to hospital. They stated stories of some of their colleagues were dropped unfairly. Operationally, they will be motivated if the college administration signs contracts with Qatar University for bridging and with local institutions for ensuring jobs to students after graduation. The following table shows what the respondents prefer the administration to do in order to arouse their motivation to learn.

Table (2): Adjectives and actions that the respondents used to describe the sort of administration that enhances their motivation

\begin{tabular}{|c|c|}
\hline djectives & Actions \\
\hline $\begin{array}{l}\text { Flexible policies, helpful, understanding c } \\
\text { students' social circumstances, cooperativ } \\
\text { with students, respectful, fair, provider } \\
\text { logistics and facilities. }\end{array}$ & $\begin{array}{l}\text { Permit using dictionaries in exams, permit mixing some Arabic in class when necessary, } \\
\text { respect students, respect students' culture, give clear rules, consider students affairs } \\
\text { when issuing rules, cooperate with local institutions as Qatar University, reconsider } \\
\text { attendance rules, issue new rules for exams: timing and use of dictionaries }\end{array}$ \\
\hline
\end{tabular}

"Being flexible" "reconsider attendance rules" were two most repeated features that the respondents think the administration should do to arouse their motivation to love coming to the college. Here are some quotations:

Student: they should consider our conditions. For example, I live very far from the college. I sometimes come late because of the traffic jam. I am married and I have children, but, they don't consider this. I think if the administration should be flexible but not to be very easy and lenient.

Student: yes. The rules are difficult for us. I mean when I am sick in hospital, they put me absent in the engrade. This is unfair.

Student: I don't think the administration tyrant. They are flexible. But, for the attendance policy, I don't like it. They don't think of us. They are unfair in this. We have children and sometimes we can't come on time because of traffic. I sometimes I hate the college for this.

Student: Yes. The rules of tardiness are unfair for us. This sometimes makes me think to leave this college. I sometimes need to be absent because my daughter is very ill, but I come to college because I am afraid they will drop me.

Student: Yes, for example, to give us scholarships, to change CCQ to a university. Of course, this will motivate us more 
and makes me like to study in this college. This is excellent thing. It is good to continue and have a degree in the college

Student: Now they gave us special break for praying. In the past, they didn't give us prayer time.

\subsubsection{Results relating to the respondents' perspectives of the role of administration to enhance their motivation}

The respondents stressed the idea that their classmates have much to do to enhance each other motivation. Likewise, they use certain adjectives and action verbs that illustrate their beliefs. The following table and quotations illustrate their perspectives.

Table (3): Adjectives and actions that the respondents used to describe the sort of classmates that enhances their motivation:

\begin{tabular}{|l|l|}
\hline Adjectives & Action Verbs \\
\hline $\begin{array}{l}\text { Interdependent, cooperative, honest, not noisy, not } \\
\text { dominant, few in number, trustable, not selfish, active, } \\
\text { friendly, sociable, intimate }\end{array}$ & $\begin{array}{l}\text { Urge each other, support each other, cooperate, not compete in a } \\
\text { dishonest way(integrity), exchange ideas and help, belong to the same } \\
\text { age, speak English, respect each other }\end{array}$ \\
\hline
\end{tabular}

\footnotetext{
Student: Some students are so noisy in class. You feel they didn't come to study. They only came to chat. This makes me nervous. I stopped doing many things in my life to come to the college. I want to learn. But some students make you hate the college. I have a purpose.

Student: because I feel I benefit from the students in the group and they benefit from me.

Student: To change the types of tables, to change the arrangement of the tables.

Student: Some students are selfish. They don't want others to learn. So they want to answer all the questions alone.

Student: Yes, when the students are active and communicate well with each other, I will be happy. But, there are some old students in class and we can't communicate with them easily. She is like my mother. How can I interact with her? One of my students dropped the term because she wasn't happy with her classmates.

Student: First, they should speak English with me. We should have good relationships with each other. We should respect each other and laugh with each other.
}

\subsubsection{Results relating to the respondents' perspectives of the effect of classroom environment to enhance their motivation}

Concerning the classroom environment, all the respondents said that four characteristics of classrooms motivate them to come to college. These characteristics are: large classrooms, not overcrowded, well-equipped with technological aids, clean and well furnished with comfortable seats and beautiful curtains.
Student: If the classroom is always clean, the curtains are good, the computer, the projector, all these help me to like the class. I like the cafeteria and to spend time with my friends.
Student: Yes. If the classroom is large, there are beautiful curtains; there is the computer, the projector as we have in our class all these help me to like the class. I like the cafeteria but I hope they serve better food.

\subsubsection{Results relating to the respondents' perspectives of the role of families to enhance their motivation}

There was a unanimous agreement in the respondents' answers as related to the influence of their families in enhancing their motivation. They all stated that their families encouraged them to study English. This encouragement took the form of verbal support through giving advice and motivating words. In addition, students pointed out that their family support also took a behavioral form through following up their academic progress by contacting the college from time to time, helping them in their homework, providing them with appropriate atmosphere and setting for studying at home, providing them with tutoring when necessary and sending them to study abroad, facilitate transportation means for them to go to the college, and giving them freedom to choose the topic they want to specialize in at college. All the students declared that financial rewards from their family has never been a way to motivate them. They added that they are studying English because they love it. The respondents highlighted the type of support their families provide to them to arouse their motivation. Following are some quotations extracted from the respondents' own speech.

Student: To send me to study abroad.

Student: To send me to study in educational centers or to bring for me a tutor to teach me at home and to encourage 
me to speak English more.

Student: They encouraged me a lot. I was hesitant to study English or not. But, they encouraged me and gave me incentives to study English in this college.

Researcher: well. What kind of help and encouragement do they provide to you: financial or verbal support and encouragement? Have they ever promised to give you money or to buy you something valuable?

Student: My mother encourages me to study the English Language. She always tells me that I have to understand all the English words of the people around me because the majority of Qatari people speak English nowadays. They don't speak Arabic.

Student: No. They only support me and encourage me.

Student: Encouragement, encouragement. They always say use English wherever you go.

\subsubsection{Results relating to the respondents' perspectives of the role of families to enhance their motivation}

The respondents' answers reveal that they are integratively motivated. Six of them are working in the morning and join the college evening classes. They stressed the fact that having goals in life motivates them. Self-confidence insistence, persistence, and honest competition with classmates are factors that enhance their abilities as all declared. Following are quotations of the respondents' ideas of how they themselves arouse their own motivation to learn English.

Quotations:

Student: I find it important to learn English. I need to communicate with the outside world especially when it is work where you deal with multi nationalities.

Student: I think of what I myself want. I see what the other negative people are telling me .Some people say to me," what do you want? You can't do anything. You are old. Stop studying. You are working and studying. That's enough. Look at yourself you are always tired. That's enough. Stop going to college.

Student: I am a person who always blame myself if I don't do what I have to do.

Student: Many times. But I start also to say that I can work and study. I encourage myself to go to college because I have a purpose.

Student: I want from my heart to study English. No one forced me to study English or to choose this college. I chose it. Student: I want English. No one said to me go and study English or to choose this college. I chose it. But when I am upset with one of the teachers because she is unfair and does not respect us, I am absent.

Student: practice, practice. I have to use English when talking with my classmates. I have to practice English at home and at work. I am working. I am a manager. I have to use English. I try to make everything around me in English. I try to set up the language of my mobile in English. I sent my emails in English. I watch English programs on TV. I never read the translation.

Student: I want to enhance myself ego. I want to prove myself as an efficient member in society. The country needs us to work hard. Not only men should build their country. We should cooperate.

\section{Discussion}

The qualitative analysis that has been conducted to the respondents' answers in the interviews revealed that there are many factors that influence their motivation positively or negatively. The results cannot be generalized as a qualitative study is always subjected to the interpretations of the data analyst and the size of the sample. However, the results may constitute a basis which opens up new insights for further research. The grounded theory approach implemented in conducting all stages of the interviews has helped the researcher to reach a set of prepositions that are similar to the hypotheses in quantitative research. Propositions indicate generalized relationships between a category and its concepts and between discrete categories (Strauss and Corbin, 1990(as cited in Pandit, 1996; Noble and Smith, 2013). The following prepositions were extracted from the in-vivo codes:

1. A teacher is motivationally influential when s/he shows affective, professional, academic and managerial potentials. Affectively, he should be friendly, sociable, cheerful, encouraging and inspirational. Professionally, s/he should vary the teaching methodology and be eclectic. Academically, he should have linguistic competence and knowledge. Managerially, he should be firm but fair in managing the class.

2. A classmate is motivationally influential when he ensures intimacy, cooperation, and honest competitions.

3. An administration entity is motivationally influential when showing fair flexibility, consideration, and logistic provision.

4. A family is motivationally influential when showing encouragement and support to their sons and daughters.

5. A student can be self-motivated when being goal-oriented, hard-working, persistent, and positively-attitudinal to learning English. 
Generally, certain words were repeated many times by the respondents, which highlight their perspectives of what arouse their motivation to learn English. The phrase "respect us and our culture" was repeated 15 times when talking about teachers. Likewise, the phrase "teach us well and use technology" was used by all respondents when talking about teachers. Similarly, the word "encouragement" was repeated when talking about families; the word "cooperative" was mentioned repeatedly when talking about classmates; the phrase "flexible and fair rules and policies" was used several times when talking about the administration; and finally the word "goal" was used to talk about their own role to enhance their motivation.

The results of the qualitative part of the current study are congruent with Dadi's study, 2011 and Qashoa, 2006 who conducted mixed method research on Omani students and found out that teachers influenced students' motivation to learn English more than other factors as families, and classmates. Similarly, Hallawa (2011) explored the factors which influence Al-Ein college students' motivation to learn from students' perspective. A total of 232 students (162 females $(70 \%)$, and 70 males (30\% participated in this study by responding to the instrument. The results of Hallawa's study helped the instructors to know the best ways to arouse their students' motivation to learn at the college.

\section{Implications of the Study Findings}

To raise students' motivation, the following recommendations can be raised:

1. Provide students with opportunities to build social relationships in the context of the classroom, namely between teacher and students and among students themselves. This rapport can be achieved through mutual respect to the individuals and to their culture, and by creating a pleasant, relaxed and cheerful classroom climate where students are encouraged to build their learning autonomy. Teachers need to be facilitators not fanatically authoritative. Engaging students in interesting academic group activities has a great impact on students' motivation to learn. More importantly, differentiation instruction where the teacher is eclectic in his teaching methods so as to cater for students' individual differences.

2. Parents' support is always the key for students' success.

3. Administration needs to be more flexible and considerate while issuing the college policies, encouraging students to participate in taking decisions. This can be achieved by launching elections to elect students' representatives- "senates or parliaments"- to share in the college policies.

4. Students have to be encouraged to be goal-oriented. This will give them motives and incentives to overcome difficulties to acquire language. They should also be helped to have positive attitudes to the others' cultures.

\section{References}

Abdesslem, H. (2002). Redefining Motivation in FLA and SLA. Cahiers Linguistiques d'Ottawa, 30, 1-28.

Adams, A. \& Cox, A.L. (2008). Questionnaires, in-depth interviews and focus groups. In: Cairns, Paul and Cox, Anna L. eds. Research Methods for Human Computer Interaction. Cambridge: Cambridge University Press, 17-34.

Al-Quyadi, A. (2000). Psycho-sociological variables in the learning of English in Yemen, Ph.D Thesis, Bhagalpur University.

Balkır, N. B., \& Topkaya, E. Z. (2009). Exploring the effects of learner training on motivation. Asian EFL Journal, 37, 1-40. Retrieved from http://www.asian-efl-journal.com/pta on 5 March, 2015.

Barriball, L. and While, A. (1994). Collecting data using a semi-structured interview: a discussion paper. Journal of Advanced Nursing, 1994, 19, 328-335.

Berg, B. (2001). Qualitative research methods for the social sciences. 4th edition, A Pearson Education Company, Long Beach, California, USA. Online book. Retrieved from https://mthoyibifiles.wordpress.com/2011/05/qualitative-research-methods-for-the-socialsciences_bruce---berg-2001.pdf

Brown, D. (1994). Principles of Language Learning and Teaching. Indiana: Prentice Hall.

Campbell, J., Quincy, C., Osserman, J. and Pedersen, O. (2013). Coding in-depth semi-structured interviews: problems of unitization and intercoder reliability and agreement, Sociological Methods \& Research, 42(3),294-320. Retrieved on October 20,2016 from http://sociology.dartmouth.edu/sites/sociology/files/coding_in_depth_semi.pdf

Celce-Murcia, M. (1991). Teaching English as a Second or Foreign Language. Second Edition. New York: Newbury House Publishers.

Cohen, D. (2006).Qualitative research guidelines.Semi-structured interviews. New Jersey: Robert Wood Johnson Foundation. Retrieved from http://www.sswm.info/sites/default/files/reference_attachments/COHEN\%202006\%20Semistructured\%20Interview.pdf

Cohen, L., Manion, L., \& Morrison, K., (2007).Research Methods in Education, London: RoutledgeFalmer, 6th Edition

Dadi, S, (2011). "Factors impacting on the motivation of Omni students to learn English as an L2." Online Ph. D. dissertation, 2011 De Montfort University, UK. Retrieved on March 19, 2016 from https://www.dora.dmu.ac.uk/bitstream/handle/2086/5997 IFINAL\%20\%5Bpost\%20viva-for-printing\%5D.pdf?sequence=1

Deci, E. \& Ryan, R. (1994). Promoting Self-Determined Education. Scandinavian Journal of Educational Research, 38(1), 3-14. 
Deci, E. \& Ryan, R. (2000). The 'what' and 'why' of goal pursuits: Human Needs and the Self-Determination of behavior. Psychological Inquiry, 11(4), 227-68.

Dejnozka, E.L.; Kapel, D.E.; Gifford, C.S. ; and Kapel, M.B. (1991) American Educator' Encyclopedia (Revised Edition), Greenwood Press.

Denzin, N. and Lincoln, Y. (2011). The Sage handbook of qualitative research. Sage Publication Ltd. USA.

Dörnyei Z. and Ushioda Z. (2011). Teaching and Researching Motivation. Harlow, England: Pearson Longman.

Dörnyei, Z. (1998). Motivation on second and foreign language learning. Language Teaching, 31:3, 117-135.

Dörnyei, Z. (2001). Teaching and researching motivation. Essex, UK: Pearson Education Limited.

Dörnyei, Z. (2010). Teaching and Researching Motivation. London: Routledge.

Dornyei, Z., \& Clement, R. (2001). Motivational characteristics of learning different target languages: results of a nationwide survey. In Z. Dornyei \& R. Schmidt (Eds.), Motivation and second language acquisition (pp. 399-432). Honolulu, HI: Second Language Teaching and Curriculum Center, University of Hawaii at Manoa.

Gardner, R. C. (1985). Social Psychology and Second Language Learning: The role of attitudes and motivation. London: Edward Arnold.

Gardner, R. C. (2001). Integrative motivation and second language acquisition, in Z. Dornyei \& R. Schmidt (eds.), Motivation and second language acquisition (pp. 1-19).Honolulu, HI: The University of Hawaii, Second Language Teaching and Curriculum Center.

Guilloteaux, M. \& Dornyei, Z. (2008). Motivating Language Learners: A classroom oriented investigation of the effects of motivation strategies on student motivation. TESOL Quarterly, 42(1), 55-77.

Halawa,I. (2011). Factors influencing college students' Motivation to learn from students' perspective. Education,132 (2), p.379

Hanrahan, Mary. (1998). The effect of learning environment factors on students' motivation and learning. International Journal of Science Education, 20 (6) p 737-753

Karahan, F. (2007). Language attitudes of Turkish students towards the English language and its use in Turkish context. Journal of Arts and Sciences Say, 7 May, 73-87.

Kindermann, T. (2007). Effects of naturally existing peer groups on changes in academic engagement in a cohort of sixth graders. Child Development, 78(4), $1186-1203$.

King, Andrew. (2008). In vivo coding. In Liza Given: The Sage Encyclopedia of Qualitative Research Methods. Online Pub. 2008, printISBN: 9781412941631, publisher:SAGE Publications, Inc.from DOIhttp://dx.doi.org/10.4135/9781412963909

Laforest, J. (2009). Guide to organizing semi-structured interviews with key informant. Charting a course to save living. Quebec: Government Quebec. Retrieved on March,2016 from http://www.inspq.qc.ca/pdf/publications/guide_entretien_vol11_eng.pd

Lee, R. M., \& Fielding, N. G. (1991). Computing for qualitative research: Options, problems and potential. In N. G. Fielding \& R. M. Lee. (Eds.), Using computers in qualitative research (pp. 1-13). London: Sage. Retreived on April 2016 from https://books.google.com.qa/books?id=P5XurpLU_H4C\&pg=PA458\&lpg=PA458\&dq=Lee,+R.+M.,+\%26+Fielding,+N.+G.+(1991).+C omputing

Melendy, G. A. (2008). Motivating writers: The power of choice. Asian EFL Journal, 10(3), 187-198. Retrieved from http://www.asian-efl-journal.com/ on 8 March, 2016.

Noble, H. and Smith, J. (2013). Qualitative data analysis: a practical example. RCNi and Evidence-Based Nursing,10.1136/eb-2013-101603. Retrieved in April 2016 from http://ebn.bmj.com/content/early/2013/11/20/eb.

Norris-Holt, J. (2001). Motivation as a contributing factor in second language acquisition. The Internet TESL Journal, Vol. vii, 6. Retrieved in March 2016from http://itesl.org/Articles/Norris-Motivation.html.

Pandit, N. (1996). The Creation of theory: a recent application of the grounded theory method. The Qualitative Report, 2(4), pp.1-20 http://www.nova.edu/ssss/QR/QR2-4/pandit.html

Popping, Roel. 2010. Some views on agreement to be used in content analysis. Quality and Quantity, (44), pp.1067-1078.

Qashoa,S.(2006). Motivation among learners of English in the secondary schools in the Eastern coast of the UAE.Online MA Thesis.

Richards, J. \& Rogers, T. (1986). Approaches and Methods in Language Teaching. A Description and Analysis. Cambridge: Cambridge University Press.

Shank, D., and Brown, L. (2007). Exploring educational research literacy. NewYork: Routledge

Silverman, D. (1993). Interpreting qualitative data: Methods for analysing talk, text and interaction. London, California \& New Delhi: SAGE Publications. Online book available at http://www.amazon.co.uk/Interpreting-Qualitative-Data-Analysing-Interaction/dp/0761968652

Strauss, A. and Corbin, J. (1990) Basics of Qualitative Research: Grounded Theory Procedures and Techniques (London: Sage).

Strauss, A. and Corbin, J. (1998) Basics of Qualitative Research Techniques and Procedures for Developing Grounded Theory (2nd edition). Sage Publications: London.

Tahaineh, Y. and Daana, H. (2013). 'Jordanian Undergraduates' Attitudes Towards Leaning English in EFL Context'. International Review of Social Sciences and Technologies.Vol. 4, No. 2. (2013), pp. 159-180.

Troudi, S. and Alwan, F. (2010). Teachers' feelings during curriculum change in the United Arab Emirates: Opening Pandora's box. Teacher Development, 14(1), 107-121.

Troudie, S. (2009). The Effects of English as a medium of instruction on Arabic as a language of science and academia, In Wachob, P. (2009). Power in the EFL classroom: Critical pedagogy in the Middle East. Cambridge: Cambridge Scholars Publishing.

Vaezi, Z. Language learning motivation among Iranian undergraduate students, World Applied Sciences Journal, 5(1) (2008), 54-61.

Wu, W. C. V., \& Wu, P. H. N. (2008). Creating and authentic EFL learning environment to enhance student motivation to study English. Asian EFL Journal, 10(4), 211-226. Retrieved in March 2016 from www.asian-efl-journal.com/ on Feb 15, 2016. 